\title{
Breast Cancer Guidelines in Canada: A Review of Development and Implementation
}

\author{
Amy Folkes $^{\mathrm{a}}$ Robin Urquhart ${ }^{\mathrm{a}} \quad$ Louise Zitzelsberger $^{\mathrm{b}} \quad$ Eva Grunfeld $^{\mathrm{a}}$, b, c \\ a Cancer Outcomes Research Program, Cancer Care Nova Scotia, Halifax, Nova Scotia, \\ ${ }^{\mathrm{b}}$ Canadian Partnership Against Cancer, \\ c Department of Medicine, Dalhousie University, Halifax, Nova Scotia, Canada
}

\section{Key Words}

Breast cancer - Clinical practice guidelines .

Knowledge translation

\section{Summary}

A series of specific clinical practice guidelines (CPGs) were published in Canada in 1998. A primary objective of these 'Clinical Practice Guidelines for the Care and Treatment of Breast Cancer' was to decrease the variation in breast cancer care across the country. Prior to this, researchers found moderate compliance with consensus recommendations for breast cancer therapies in several Canadian provinces. However, a recent study concluded that the publication of the Canadian CPGs did not reduce variations in surgical care for breast cancer. If guidelines are to achieve their intended objectives, they must be implemented in ways that support, encourage, and facilitate their use. Evidence strongly suggests the simple publication and passive dissemination of CPGs are usually ineffective in changing how physicians actually care for patients. CPG implementation, therefore, requires active knowledge translation processes to ensure that the evidence is relevant to all with a stake in bettering breast cancer care. For example, implementation strategies that use computerized CPGs can make evidence-based decision-making routine practice in the clinical setting. The breast cancer community can also work with the newly formed Canadian Partnership Against Cancer to find ways to more successfully support and facilitate guideline use considering the local context.

\author{
Schlüsselwörter \\ Brustkrebs · Klinische Praxis, Richtlinien . \\ Umsetzung von Wissen in Verhalten
}

\section{Zusammenfassung}

Eine Reihe spezifischer klinischer Praxisrichtlinien (clinical practice guidelines, CPGs) wurden 1998 in Kanada veröffentlicht. Eines der Hauptziele der 'Clinical Practice Guidelines for the Care and Treatment of Breast Cancer' war die Reduzierung von landesweiten Unterschieden in der Betreuung von Brustkrebspatienten. Bis dahin hatten Forscher in mehreren kanadischen Provinzen eine nur mäßige Einhaltung der Konsensus-Empfehlungen für die Behandlung von Brustkrebs festgestellt. Eine neuere Studie kam jedoch zu dem Schluss, dass die Veröffentlichung der kanadischen CPGs die Unterschiede in der chirurgischen Betreuung von Brustkrebspatienten nicht reduziert hat. Damit Richtlinien ihre Ziele erreichen können, müssen sie auf eine Art und Weise implementiert werden, die ihre Nutzung unterstützt, gefördert und erleichtert. Es gibt deutliche Hinweise darauf, dass die einfache Veröffentlichung und passive Verteilung von CPGs zumeist nicht zu Änderungen in der Patientenbetreuung durch die behandelnden Ärzte führen. Die Implementierung von CPGs setzt daher eine aktive Umsetzung von Wissen in Verhalten (knowledge translation) voraus, um sicherzustellen, dass die getroffenen Aussagen für alle an der Verbesserung der Brustkrebsversorgung Beteiligten relevant sind. So können z.B. Implementierungsstrategien, die computerbasierte CPGs verwenden, dazu führen, dass die auf Fakten basierende Entscheidungsfindung in der Klinik zur Routine wird. Die Brustkrebs-Gemeinschaft kann des weiteren mit der neu gegründeten 'Canadian Partnership Against Cancer' zusammenarbeiten, um Wege zu finden, wie die Anwendung von Richtlinien mit Bezug auf lokale Gegebenheiten unterstützt und erleichtert werden kann.

\begin{tabular}{ll}
\hline KARGER & $\odot$ 2008 S. Karger GmbH, Freiburg \\
Fax +49 7614520714 & Accessible online at: \\
$\begin{array}{l}\text { E-mail Information@Karger.de } \\
\text { www.karger.com }\end{array}$ & www.karger.com/brc
\end{tabular}

Amy Folkes

Cancer Outcomes Research Program, Cancer Care Nova Scotia

1278 Tower Road, Room 523, 5th Floor Bethune Building

Halifax, Nova Scotia B3H 2 Y9, Canada

Tel. +1 902 473-7501, Fax -4631

E-mail amy.folkes@ccns.nshealth.ca 


\section{Introduction}

Breast cancer is the most common cancer diagnosed in women in developed countries. There have been tremendous research efforts throughout the past 2 decades that vastly improved breast cancer care and treatment options [1-3]. However, to maximize the fruits of this research for women diagnosed with breast cancer, such evidence requires the use of strategies to support its translation into practice. Clinical practice guidelines (CPG) are an important tool to facilitate evidence-based breast cancer care. In Canada, there have been several initiatives to develop breast cancer CPGs. CPGs can be defined as 'systematically developed statements to assist practitioners' decisions about appropriate health care for specific clinical circumstances' [4]. They provide an important summation of up-to-date knowledge about the best clinical practices available, supported by clinical expertise, and can be used to enhance the appropriateness of practice, provide consistency, and improve quality of care [5]. Organizations responsible for the dissemination of guidelines in Canada have acknowledged the importance of knowledge translation (KT) in this process. $\mathrm{KT}$ is essentially the exchange, synthesis, and application of knowledge to realize the benefits of research through implementation in clinical practice [6].

The objective of this article is to describe the development, implementation, and future directions of Canadian breast cancer guidelines for care and treatment. Specifically, we will review the national breast cancer initiative, the development and use of breast cancer CPGs in Canada, knowledge translation and its relevance to breast cancer CPGs, and how the Canadian cancer community is moving forward with respect to ongoing CPG development and implementation in general.

\section{Events Leading to a National Initiative}

The Canadian Breast Cancer Initiative (CBCI) began in 1992 with the publication of a parliamentary report entitled 'Breast Cancer: Unanswered Questions' [7]. The report highlighted the need for greater consistency in breast cancer services and delivery, and for overall consensus on issues involving research, prevention, and care. The report was followed by a national forum on breast cancer, which was held in Montreal in November 1993. This forum is viewed as the pivotal event which set the stage for the CBCI. The goal of CBCI was to implement strategies to improve breast cancer care in Canada, including the development of CPGs [8].

\section{Development and Use of Breast Cancer CPGs}

Following the national forum, the federal health agency funded a committee to develop evidence-based breast cancer CPGs, with one of the primary objectives being to decrease the variations in breast cancer treatment across the country [8]. Variations in care emerged as a concern for breast cancer patients [8], and a number of Canadian studies substantiated that variations existed both for surgery $[9,10]$ and for subsequent radiation therapy [9]. CPGs were considered a tool to improve both consistency and quality of care. Accordingly, the committee, consisting of breast cancer health professionals from across the country, identified specific topics for which CPGs were needed. The development process was rigorous and comprehensive with each CPG undergoing 20-40 cycles of review and revision [11]. The recommendations were based on the best available evidence. Five levels of evidence were specified, and the level of evidence was provided for each of the recommendations [11]. The result was the 'Clinical Practice Guidelines for the Care and Treatment of Breast Cancer', a series of 16 specific CPGs, each with an accompanying lay version for patients and their families (table 1). The lay versions contained a summary of content included in the health professional versions, but differed in detail and terminology. The principle medium for the dissemination of these guidelines was through print and online versions of the Canadian Medical Association Journal (CMAJ) [12,13], with the Canadian Cancer Society also distributing the lay versions through its Cancer Information Service [14]. The first 10 were published in 1998, with new CPGs and revisions published in subsequent years. The most recent update was in 2005 on followup care [15]. Corresponding with this national initiative, several provincial cancer agencies in Canada have developed and implemented their own guidelines and consensus recommendations for breast cancer management $[16,17]$. These are updated periodically and distributed locally to cancer care professionals within the respective provinces.

The big question remains, however, whether these guidelines and others [18] have improved care and reduced variation across Canada: simply put, have they actually changed practice? Before the 1998 publication of the Canadian guidelines, researchers found moderate compliance with consensus recommendations for breast cancer therapies in several Canadian provinces. Olivotto et al. [19] reported high compliance rates with provincially-distributed guidelines on adjuvant therapy for women with node-negative breast cancer. In the same province, Chua et al. [20] found that publication of clinical trials followed by a coordinated guideline implementation process was associated with improvements in the use of regional radiotherapy for women with node-positive breast cancer. Reports from another region of Canada [21] indicated that a high proportion of women diagnosed with node-negative breast cancer in the early 1990s received systemic therapy consistent with the 1992 St. Gallen recommendations. However, compliance was high prior to the release of the 1992 recommendations, and neither the overall use of systemic therapy nor the consistency with recommendations changed in the year following the St. Gallen conference [21]. In terms of surgery, Iscoe et al. [22] reported significant changes in surgi- 
Table 1. Canadian clinical practice guidelines for the care and treatment of breast cancer: health professional and corresponding patient versions, dates indicate most recent version/update

Health Professional $\quad$ Patient $^{\mathrm{a}}$

1. The palpable breast lump: information and recommendations to assist decision-making when a breast lump is detected (1998)

2. Investigation of lesions detected by mammography (1998)

3. Mastectomy or lumpectomy? The choice of operation for clinical stages I and II breast cancer (1998; updated 2002)

4. Axillary dissection (1998; 2001 decision: no update required)

5. The management of ductal carcinoma in situ (DCIS) (1998; updated 2001)

6. Breast radiotherapy after breast-conserving surgery (1998; updated 2003)

7. Adjuvant systemic therapy for women with node-negative breast cancer (1998; updated 2001)

8. Adjuvant systemic therapy for women with node-positive breast cancer (1998; updated 2001)

9. Follow-up after treatment for breast cancer (1998; updated 2005)

10. The management of chronic pain in patients with breast cancer (1998; updated 2001)

11. Lymphedema (2001)

12. Chemoprevention of breast cancer (2001)

13. Sentinel lymph node biopsy (2001)

14. The role of hormone replacement therapy in women with a previous diagnosis of breast cancer (2002)

15. Treatment for women with stage III or locally advanced breast cancer (2004)

16. Locoregional post-mastectomy radiotherapy (2004)
Patient $^{\mathrm{a}}$

1. Investigation of a breast lump that can be felt (1998)

2. Investigation of an abnormality that is discovered by mammography (1998)

3. Mastectomy or lumpectomy? Choosing the most appropriate operation for early invasive breast cancer (1998; updated 2002)

4. Removal of lymph nodes during breast cancer surgery (1998)

5. Ductal carcinoma in situ (DCIS) (1998; updated 2001)

6. Radiation therapy after lumpectomy (1998; updated 2003)

7. Anticancer drug treatment for node-negative breast cancer (1998; updated 2001)

8. Adjuvant systemic therapy for women with node-positive breast cancer (1998; updated 2001)

9. Follow-up care after breast cancer treatment (1998; updated 2005)

10. Management of persistent pain after breast cancer treatment (1998; updated 2001)

11. Management of lymphedema related to breast cancer (2001)

12. Chemoprevention and breast cancer (2001)

13. Sentinel lymph node biopsy (2001)

14. The use of hormone replacement therapy (HRT) by women who have had breast cancer (2002)

15. Treatment for women with stage III or locally advanced breast cancer (2004)

16. Radiotherapy after mastectomy (2004)

aThe patient version guidelines are accompanied by 3 additional documents: Where can I find support?, What is a clinical trial?, and Where can I find more information?

cal practice following publication of the National Surgical Adjuvant Breast Project trial findings, which compared outcomes following modified radical mastectomy and breast-conserving surgery for women with early-stage breast cancer. Although these changes did not result from a CPG publication, they demonstrate that general awareness of trial results can effect changes in physician behavior. Despite the above-noted findings, however, it is important to recognize that it is difficult to separate the influence of published guidelines from the influence of the growing body of literature on therapies for breast cancer. Indeed, in many regions, clinical practice may have been changing for some time, with the introduction of guidelines providing only modest contributions to the growing compliance with research evidence. For example, the studies investigating the use of systemic therapy for node-negative breast cancer $[19,21]$ examined therapy decisions in the late 1980s and early 1990s, a time period that narrowly followed the publication of a number of articles investigating the effectiveness of adjuvant systemic therapies for women diagnosed with node-negative breast cancer [23-27].

Since the publication of the first series of the Canadian breast cancer guidelines in 1998, few researchers have systematically evaluated their effects on clinical practice and assessed whether physicians have adopted the recommendations. In a recent study, Latosinsky et al. [28] examined variations in 4 measures of surgical care for patients diagnosed with breast cancer both before and after the publication of the relevant CPGs and concluded that neither the province-wide rates nor variations in these rates among surgeons were affected by the guidelines. The results also suggested again that, for some procedures, changes in practice may be more reliant on steadily increasing bodies of knowledge than on the publication and dissemination of CPGs [18]. Similarly, the publication of CPGs did not reduce variations in surgical care over the study period (1995-2003), indicating that the guidelines are not sufficiently meeting their objectives to encourage greater consistency in practice for surgical care. Others have reported similar findings for surgical care [29].

The Canadian breast cancer guidelines [12] are unique in that they transcend the surgical and therapy realm to address issues such as decision-making once a breast lump is detected [30] and routine follow-up care following treatment for breast cancer [15]. To our knowledge, no one has published data on the effectiveness of these CPGs, or on whether the lay versions are meeting the needs of patients and their families (and, indeed, whether patients and families are even accessing these docu- 
ments). Given that patient advocacy was a major impetus for the CBCI, the effect of evidence-based information on patient decision-making and satisfaction with care deserves attention. Although funding for the Canadian breast cancer guidelines has now ended, the CPGs remain on the CMAJ website and can be accessed by physicians and the general public. Adherence to breast cancer guidelines and effects upon practice and eventual outcomes remain challenging to evaluate. However, despite the specific difficulties in assessing outcomes, there is an extensive body of literature on the gap between the development of CPGs and their implementation, as well as on strategies to improve their implementation [31-33].

\section{Knowledge Translation and Breast Cancer CPGs}

The Canadian breast cancer guideline initiative recognized several key elements of guideline development including wide-ranging participatory development processes, sound evidence base, and continual evaluation and revision. Still, if guidelines are to achieve their intended objectives, they must be implemented in ways that support, encourage, and facilitate their use. Indeed, to expect the simple publication and passive dissemination of guidelines to change clinical practice is unrealistic [18] in light of what we know about guidelines and physician behaviour: systematic reviews strongly suggest that while passive dissemination strategies (e.g., guideline publication, mail-outs to physician offices) may raise awareness of optimal care practices, when used alone they are usually ineffective in changing how physicians actually care for their patients [31]. Accordingly, guideline implementation requires active KT processes, involving the tailoring of the guideline and working to overcome barriers to behaviour change [34], to ensure that evidence is relevant to all with a stake in bettering breast cancer care $[31,32,35,36]$. Strategies such as audit and feedback targeted at specific physicians and delivered by peers or opinion leaders, office reminder systems, academic detailing, and multi-faceted interventions have been shown to be moderately effective at changing practice [31, 32, 35].

The National Cancer Institute of Canada acknowledges the importance of $\mathrm{KT}$ in the implementation of research [37]. However, it is important to remember that KT strategies are dynamic and require iterative frameworks with implementation considered throughout all stages of the planning, development, and dissemination processes [38]. When designing an implementation strategy, barriers to behaviour change, such as structural (e.g., staff workload and financial resources) and attitudinal (e.g., acceptance of CPGs and willingness to change) factors, should be considered [35]. While there are no magic bullets for physician behaviour change, CPGs are more likely to be effective if they are adapted to fit local resources and systems $[36,38]$. The CMAJ, which is the primary dissemination medium for numerous CPGs, including the Canadian breast cancer guidelines, emphasizes the need to consider both local environment and available resources during the development stages as well as the savvy to put together a development team that consists of the appropriate mix of stakeholders [38].

\section{Moving Forward with Breast Cancer CPGs in Canada}

Recently, in Canada, a national cancer control strategy has been initiated: the Canadian Partnership Against Cancer [39]. A key area of focus for the Partnership is to facilitate and accelerate implementation of knowledge in cancer control [39]. In Canada, there is no national cancer guideline development body other than focused initiatives such as the breast cancer guidelines [13]. However, guidelines have a place under the Partnership via the Cancer Guidelines Action Group (CG AG). Its members include cancer care professionals, researchers, consumers, KT experts, methodologists, guideline experts, policy makers, cancer agency representatives, and industry representatives. The CG AG works to find 'strategies to facilitate and add value to ongoing initiatives in guideline activities - rather than competing with or replacing them - and to promote further activities by building capacity that will gradually increase critical mass, access to expertise and quality of cancer guidelines across the nation' [40].

Similar to the case of the breast cancer guidelines, national guidelines are seen as a way to make care more consistent across a country. Unless there is recognition of barriers that exist at local levels (e.g., resources, training) and solutions provided and/or options with respect to recommendations, the adoption of guidelines may face considerable challenges. In conjunction with the international ADAPTE Collaboration [41], the CG AG is engaged in the development of a manual and training material to assist with guideline adaptation. Adaptation refers to modifying an existing guideline to fit the organizational and cultural context of use, while addressing duplication of efforts by building on existing work [39]. It also acts to ensure that those involved in the process have a better understanding of use and appraisal of evidence, guideline development, and implementation. Beyond the adaptation project, the CG AG is working on a training curriculum to help build capacity across the country to understand the value of evidence-based products, such as guidelines, and to support evidence-based practice.

In addition to the Partnership, the next steps in breast cancer guidelines in Canada will undoubtedly involve designing implementation strategies that go beyond traditional KT approaches to innovative tools that make evidence-based decision-making (the ultimate goal of CPG development and dissemination) routine practice in the clinical setting. This includes work on standardized reporting tools [42], as well as work on computerized CPGs [43] and electronic reminder and decision-support tools. Along these lines, there is increasing awareness and demand for computerizing support of CPGs in 
health care settings. As computers become accepted everyday tools of clinical practice, there is an opportunity to translate breast cancer CPGs in electronic form. Tailoring guidelines in a form whereby only the recommendations required for a specific patient are accessed at the time and place of the clinical encounter is regarded as an effective method of influencing physicians' behavior [31,44]. Electronic CPGs have the search capabilities to do just that. Additionally, software programs with the capacity to incorporate CPGs into a patient's electronic medical record, and those that provide reminder support systems, would likely assist physicians and health care professionals with evidence-based decision-making for that particular patient [5,31]. Abidi et al. [43] are currently developing a methodology to computerize a CPG by using the Canadian breast cancer guideline on follow-up care [15].

While computer-based strategies have proven effective in terms of guideline dissemination and implementation, it is imperative that CPGs are widely disseminated to all physicians [45]. A 2007 College of Family Physicians of Canada survey [46] found that approximately $73 \%$ of family physicians have access to the internet and therefore can locate online versions of CPGs in their offices. While this number may increase over the coming years, many family physicians continue to lack internet access in their patient care settings; the reasons for this include the costs associated with equipping physicians' offices with the appropriate hardware, difficulty establishing connections in rural locations (e.g., dial-up access), and general resistance to change. However, internet accessibility does not guarantee that physicians have the specific computing skills needed to access and utilize CPGs online. Consequently, mail-outs have remained the most viable form of $\mathrm{CPG}$ dissemination $[33,45]$. While this method addresses the need for wide dissemination, it has been shown to be ineffective for KT purposes [31]. Certainly, technical issues need to be addressed before widespread use of electronic CPGs and computer-generated reminder systems occurs [47]. Costs and accessibility remain foremost challenges in Canada, yet the programming requirements for computerizing decision-support software based on medical evidence also necessitate substantial time and resources. Collaborating with researchers in areas such as health informatics may prove valuable in this regard.

Implementation strategies are more likely to be successful when they target both the health professional and the patient [48]. Research has shown that interventions involving patient education materials are effective in improving health services outcomes and maximizing the overall potential of CPGs [31, $32,48]$. Family physicians have voiced their beliefs that userfriendly, evidenced-based patient guidelines are useful in countering the misinformation accessed by cancer patients (e.g., from the internet) and in providing credibility to family physicians' cancer recommendations [45].

While the Canadian breast cancer guidelines include patient versions, recent focus has shifted toward the use of patient care plans in cancer care. This focus corresponds with the National Cancer Institute's President's Cancer Panel report [1] which recommends the use of care plans for patients who have finished treatment and are considered cancer survivors. The care plan is based on the concept that all patients should have a comprehensive care summary and follow-up plan, tailored to reflect their treatment and address their post-treatment needs [2]. A randomized controlled trial is currently underway in Canada [49] to evaluate the effectiveness of a combination of CPGs on follow-up care [15] and a survivorship care plan [2]. This is the first trial in Canada to test tailored care planning for breast cancer survivors. Given that patients have played a substantial role in Canadian-wide guideline initiatives, breast cancer patients may also prove to be valuable catalysts for improving CPG use across the country.

\section{Conclusions}

The 1998 publication of the Canadian breast cancer guidelines was a large undertaking and a significant achievement for breast cancer care in Canada. However, many of the CPGs are now outdated (some were published 10 years ago) and, like all CPGs, require ongoing review and revision. Unfortunately, funding for this initiative is no longer available. In addition, more work is warranted, particularly in the areas of KT and CPG implementation, to ensure that the original objectives of improved care and reduced variation are realized. The breast cancer community can work with the newly formed Partnership to find ways to more successfully support and facilitate guideline use considering the local context. In this paper, we have described the development, implementation, and future direction of Canadian breast cancer guidelines for care and treatment. Progress in this area will not only provide up-todate standards against which variations in care can be assessed [28], but also a means to encourage the continual goal of quality improvement in clinical practice.

\section{References}

1 President's Cancer Panel, Living Beyond Cancer: Finding a New Balance. Bethesda, MD, U.S. Department of Health and Human Services, National Institutes of Health, National Cancer Institute, 2004.

2 Committee on Cancer Survivorship: Improving Care and Quality of Life (National Cancer Policy Board): From Cancer Patient to Cancer Survivor: Lost in Transition. Washington, D.C., Institute of
Medicine and National Research Council of The National Academies Press, 2005

3 National Institutes of Health Consensus Development Conference statement: Adjuvant therapy for breast cancer, November 1-3, 2000. J Natl Cancer Inst Monogr 2001;30:5-15.

4 Committee on Clinical Practice Guidelines: Guidelines for Clinical Practice: From Development to Use. Washington, Institute of Medicine National Academy Press, 1992
5 Woolf S, Grol R, Hutchinson B, Eccles M, Grimshaw J: Clinical guidelines: potential benefits, limitations, and harms of clinical guidelines. BMJ 1999;318:527-530.

6 Canadian Institutes of Health Research: Knowledge Translation (KT) and Commercialization. www.cihr-irsc.gc.ca/e/29529.html.

7 Greene B: Breast Cancer: Unanswered Questions. Ottawa, Queen's printer, 1992. 
8 Health Canada: Report on the National Forum on Breast Cancer. Ottawa, ON, 1994.

9 Goel V, Olivotto I, Hislop TG, Sawka C, Coldman A, Holowaty EJ: Patterns of initial management of node-negative breast cancer in two Canadian provinces. CMAJ 1997;156:25-35.

10 Iscoe NA, Goel V, Wu K, Fehringer G, Holowaty EJ, Naylor CD: Variation in breast cancer surgery in Ontario. CMAJ 1994;150:345-352.

11 The Steering Committee on Clinical Practice Guidelines for the Care and Treatment of Breast Cancer: Introduction. CMAJ 1998;158:S1-S2.

12 Steering Committee on Clinical Practice Guidelines for the Care and Treatment of Breast Cancer: Clinical practice guidelines for the care and treatment of breast cancer: a Canadian consensus document. CMAJ 1998;158:S1-83.

13 Steering Committee on Clinical Practice Guidelines for the Care and Treatment of Breast Cancer: Clinical Practice Guidelines for the Care and Treatment of Breast Cancer (online).www.cmaj.ca/cgi/ content/full/158/3/DC1.

14 Canadian Cancer Society: Our Cancer Information Services (online). www.cancer.ca/ccs/internet/standard/0,3182,3172_14495_langId-en,00.html.

15 Grunfeld E, Sukhbinder D, Levine M: Clinical practice guidelines for the care and treatment of breast cancer: follow-up after treatment for breast cancer (summary of the 2005 update). CMAJ 2005;172: 1319-1320.

16 Cancer Care Ontario: Breast Cancer EvidenceBased Series and Practice Guidelines (online). www.cancercare.on.ca/english/toolbox/qualityguidel ines/diseasesite/breast-ebs.

17 British Colombia Cancer Agency: Cancer Management Guidelines: Breast (online). www.bccancer.bc ca/HPI/CancerManagementGuidelines/Breast/1Tu mourSiteTypeDemographics.htm.

18 Grunfeld E: Canadian breast cancer guidelines are as effective as possible under the circumstances. CMAJ 2007;176:785-786.

-19 Olivotto IA, Coldman AJ, Hislop TG, Trevisan CH, Kula J, Goel V, Sawka C: Compliance with practice guidelines for node-negative breast cancer. J Clin Oncol 1997;15:216-222.

20 Chua B, Olivotto IA, Weir L, Kwan W, Truong P, Ragaz J: Increased use of adjuvant regional radiotherapy for node-positive breast cancer in British Colombia. Breast J 2004;10:38-44.

21 Hebert-Croteau N, Brisson J, Latreille J, Gariepy G, Blanchette C, Deschenes L: Time trends in systemic adjuvant treatment for node-negative breast cancer. J Clin Oncol 1999;17:1458-1464.

22 Iscoe NA, Naylor D, Williams I, DeBoer G, Morgan MW, Fehringer G, Holowaty E: Temporal trends in breast cancer surgery in Ontario: can one randomized trial make a difference? CMAJ 1994; 150:1109-1115.
23 Early Breast Cancer Trialists' Collaborative Group: Effect of adjuvant tamoxifen and of cytotoxic therapy on mortality in early breast cancer: an overview of 61 randomized trials among 28,896 women. N Engl J Med 1988;319:1558.

24 The Ludwig Breast Cancer Study Group: Prolonged disease-free survival after one course of perioperative adjuvant chemotherapy for node-negative breast cancer. N Engl J Med 1989;320:491-496.

25 Fisher B, Redmond C, Dimitrov N, Bowman D, Legault-Poisson S, Wickerham DL, Wolmark N, Fisher E, Margolese R, Sutherland C, Glass A, Foster R, Caplan R: A randomized clinical trial evaluating sequential methotrexate and fluorouracil in the treatment of patients with node-negative breast cancer who have estrogen-receptor-negative tumors. N Engl J Med 1989;320:473-478.

26 Fisher B, Costantino J, Redmond C, Poisson R, Bowman D, Couture J, Dimitrov NV, Wolmark N, Wickerham DL, Fisher ER, Margolese R, Robidoux A, Shibata H, Terz J, Paterson AHG, Feldman MI, Farrar W, Evans J, Lickley HL, Ketner M: A randomized clinical trial evaluating tamoxifen in the treatment of patients with node-negative breast cancer who have estrogen-receptor-positive tumors. N Engl J Med 1989;320:479-484.

27 Mansour EG, Gray R, Shatila AH, Osborne CK, Tormey DC, Gilchrist KW, Cooper MR, Falkson G: Efficacy of adjuvant chemotherapy in high-risk node-negative breast cancer: an intergroup study. $\mathrm{N}$ Engl J Med 1989;320:485-490.

28 Latosinsky S, Fradette K, Lix L, Hildebrand K, Turner D: Canadian breast cancer guidelines: have they made a difference? CMAJ 2007;176:771-776.

29 Sheldon TA, Cullum N, Dawson D, Lankshear A, Lowson K, Watt I, West P, Wright D, Wright J: What's the evidence that NICE guidance has been implemented? Results from a national evaluation using time series analysis, audit of patients' notes, and interviews. BMJ 2004;329.

30 Steering Committee on Clinical Practice Guidelines for the Care and Treatment of Breast Cancer: The palpable breast lump: information and recommendations to assist decision-making when a breast lump is detected. CMAJ 1998;158:S3-8.

31 Grimshaw JM, Thomas RE, MacLennan G, Fraser C, Ramsay CR, Vale L, Whitty P, Eccles MP, Matowe L, Shirran L, Wensing W, Dijkstra R, Donaldson C: Effectiveness and efficiency of guideline dissemination and implementation strategies. Health Technol Assess 2004;8:1-72.

32 Gross PA, Greenfield S, Cretin S, Ferguson J, Grimshaw J, Grol R, Klazinga N, Lorenz W, Meyer GS, Riccobono C, Schoenbaum SC, Schyve P, Shaw $\mathrm{C}$ : Optimal methods for guideline implementation: conclusions from Leeds Castle Meeting. Med Care 2001;39:II85-II92.

33 Davis DA, Taylor-Vaisey A: Translating guidelines into practice: A systematic review of theoretic concepts, practical experience and research evidence in the adoption of clinical practice guidelines. CMAJ 1997;157:408-416.
34 Lomas J: Teaching old (and not so old) docs new tricks: effective ways to implement research findings, Working Paper 934. McMaster University Centre for Health Economics and Policy Analysis, Toronto, 1993.

35 Grol R: Implementing guidelines in general practice care. Qual Health Care 1992;1:184-191.

36 Oxman AD, Thomson MA, Davis DA, Haynes B: No magic bullets: a systematic review of 102 trials on interventions to improve professional practice. CMAJ 1995;153:1423-1431.

37 Grunfeld E, Zitzelsberger L, Hayter C, Berman N, Cameron R, Evans WK, Stern H: The role of knowledge translation for cancer control in Canada. Chron Dis Can 2004;25:1-6.

38 Davis D, Goldman J, Palda V: Handbook on Clinical Practice Guidelines. Canadian Medical Association, 2007.

39 Canadian Partnership Against Cancer: Canadian Partnership Against Cancer (online). www.partnershipagainstcancer.ca.

40 Browman G, Zitzelsberger L, Boscaino A: Harnessing evidence to optimize cancer control: a panCanadian approach. Oncol Exch 2005;4:22-25.

41 ADAPTE: Guideline Adaptation (online). www. adapte.org/index.php.

42 Cancer Care Ontario: Cancer System Quality Index 2007: Completeness of Pathology Reporting (online).www.cancercare.on.ca/qualityindex2007/measu rement/pathologyReports/index.html.

43 Abidi S, Abidi SSR, Hussain S, Shepherd M: Ontology-Based Modelling of Clinical Practice Guidelines: A Clinical Decision Support System for Breast Cancer Follow-Up Interventions at Primary Care Settings. 2nd World Congress on Medical Informatics (MEDINFO2007). Brisbane, IOS Press, 2007

44 Lobach DF, Hammond WE: Computerized decision support based on a clinical practice guideline improves compliance with care standards. Am J Med 1997;102:89-98.

45 Zitzelsberger L, Grunfeld E, Graham I: Family physicians' perspectives on practice guidelines related to cancer control. BMC Fam Pract 2004;5:25.

46 The College of Family Physicians of Canada. National Physician Survey 2007 (online). www.cfpc.ca English/cfpc/research/janus\%20project/default.asp? $s=1$.

47 Hunt DL, Haynes RB, Hanna SE, Smith K: Effects of computer-based clinical decision support systems on physician performance and patient outcomes. A systematic review. JAMA 1998;280:1339-1346.

48 DiCenso A, Virani T, Bajnok I, Borycki E, Davies B, Graham I, Harrison M, Logan J, McCleary L, Power M, Scott J: A toolkit to facilitate the implementation of clinical practice guidelines in healthcare settings. Hosp Q 2002;5:55-60.

49 Grunfeld E (principal investigator): A Randomized Trial of Patient-Centred Strategy to Facilitate Transition of Breast Cancer Survivors' Routine Followup from Specialist to Primary Care. Canadian Breast Cancer Research Alliance/National Cancer Institute of Canada, 2006-2010. 